\title{
El nou accelerador del CERN
}

\section{Sònia Fernandez}

Dept. de Física, Àrea d'Òptica, Facultat de Ciències, Universitat Autònoma de Barcelona

La substitució del LEP, el gran accelerador del CERN, per un altre de molt més potent, l'LHC, podria permetre aclarir alguns dels problemes actualment sense resoldre de la física de partícules.

La Segona Guerra Mundial va desplaçar el centre de gravetat de la recerca nuclear des de l'Europa occidental vers els Estats Units. El 1949, amb la finalitat d'aturar la migració cap allí dels científics europeus, de Broglie va proposar la creació d'un gran centre de recerca experimental europeu, sostingut per diversos països.

Efectivament, el 1952 es crea el Consell Europeu per a la Recerca Nuclear (CERN), que el 1954 seria substituït pel l'Organització Europea per a la Recerca Nuclear, encara que va conservar les antigues sigles. El terme "nuclear" correspon a un període molt determinat de la recerca, quan s'investigaven els components del nucli; però actualment és més adequat el nom de Laboratori Europeu de Física de Partícules.

La seu s'establiria prop de Ginebra, Suïssa. Als 12 estats que van fundar el CERN se n'hi van anar afegint d'altres fins a completar els 20 actuals (fig. 1 ), encara que en les recerques hi participen científics de tot el món.

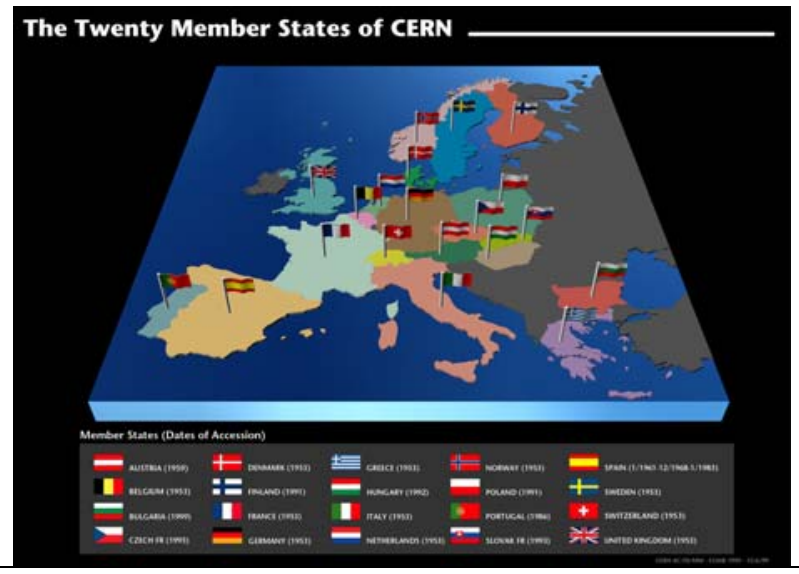

Figura 1. Els 20 Estats que actualment són membres del CERN.
L'Estat Espanyol hi va ingressar el $1961 \mathrm{com}$ a catorzè membre però en sortí el 1968. Finalment hi tornà a entrar el novembre de 1983.

\section{EI LEP i els seus fruits}

EI CERN va construir i utilitzar diversos acceleradors de partícules, alguns dels quals travessaven la frontera amb França. El 1989 entrava en funcionament el LEP (Large Electron-Positron Collider, Gran col.lisionador electró-positó): era a l'interior d'un túnel circular de $27 \mathrm{~km}$ de circumferència a uns 100 metres sota terra (fig. 2).
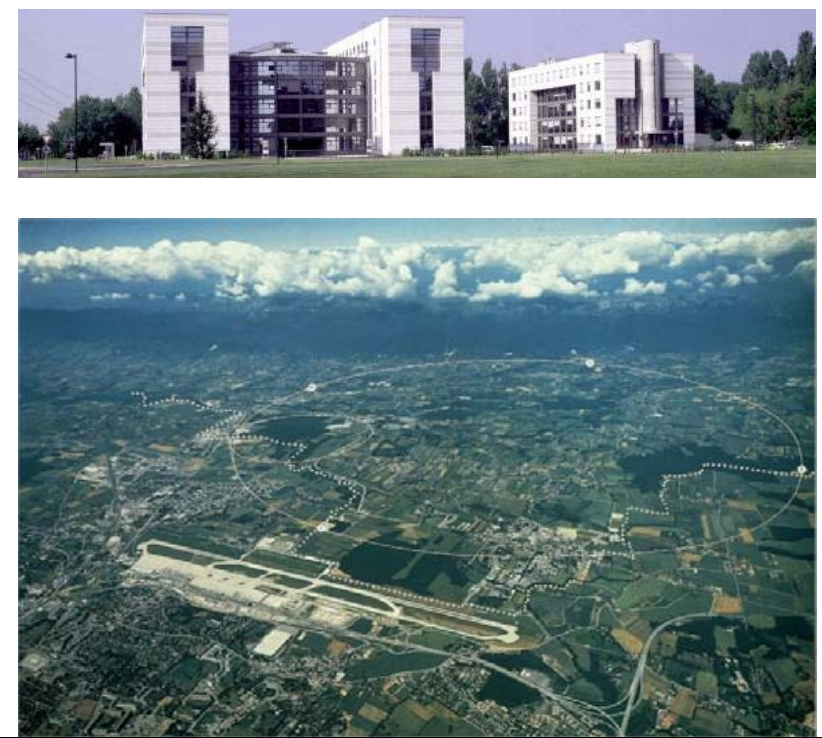

Figura 2. A dalt, edificis del CERN. A sota, localització del túnel subterrani del LEP a les rodalies de Ginebra. Les rodonetes blanques indiquen la posició dels grans detectors, i la línia de punts, la frontera franco-suïssa. 
S'hi acceleraven electrons i positrons en sentits contraris (fig. 3) per fer-los xocar frontalment i estudiar-ne els resultats a partir de les dades subministrades pels detectors (fig. 4).

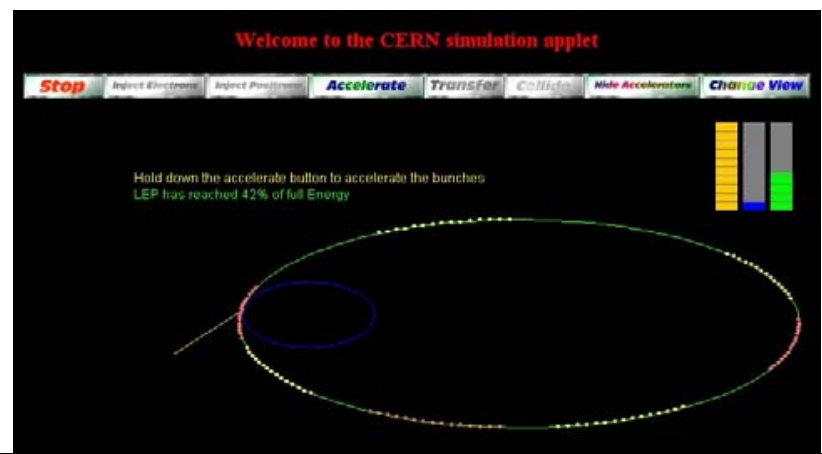

Figura 3. Applet del CERN mostrant el funcionament del LEP: grups d'electrons (groc) i de positrons (vermell) s'acceleren a l'anell principal en sentits contraris.

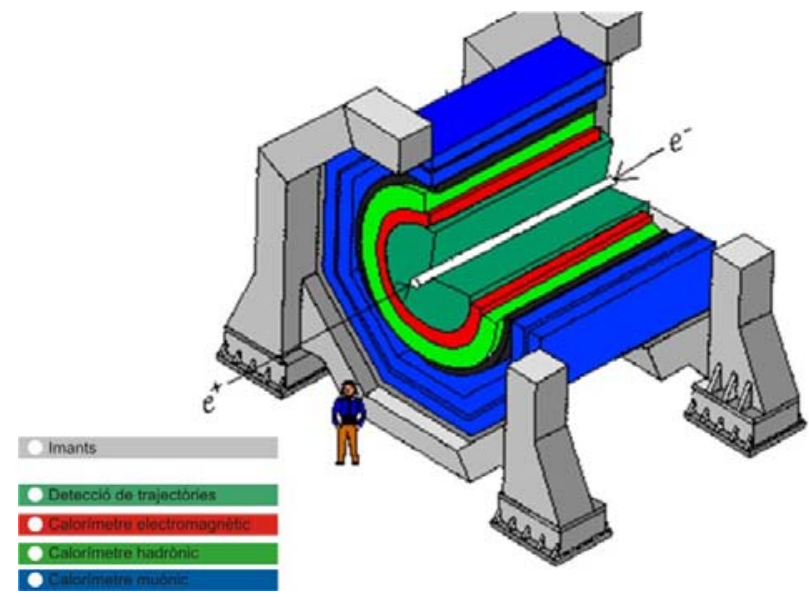

Figura 4. Diagrama d'un detector del LEP. A l'entorn del punt de col-lisió dels electrons amb els ons es disposen diverses capes per a detectar partícules en funció de la seva capacitat de penetració.

Fins al novembre del 2000 que es tanca el LEP es succeeixen una sèrie de descobriments que foren capdavanters en la física de partícules:

- 1973: Descobriment dels anomenats "corrents febles", evidenciant que els neutrins poden interactuar amb altres partícules però sense per això deixar de ser neutrins. Aquest resultat donaria un important suport a la teoria que unificava la força dèbil i l'electromagnètica: l'anomenada teoria electrodèbil (fig. 5).

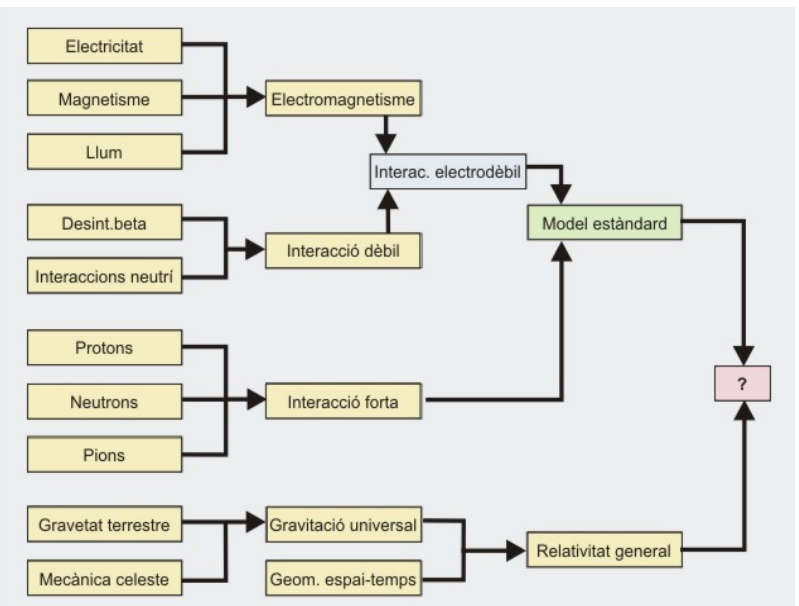

Figura 5. Procés històric d'unificació de teories sobre les forces de la naturalesa.

- 1983: Descobriment dels bosons W (el gener) $i$ Z (maig), confirmant la teoria electrodèbil. L'any següent, Rubbia i van der Meer (fig. 6) reberen per aquest motiu el premi Nobel de física.

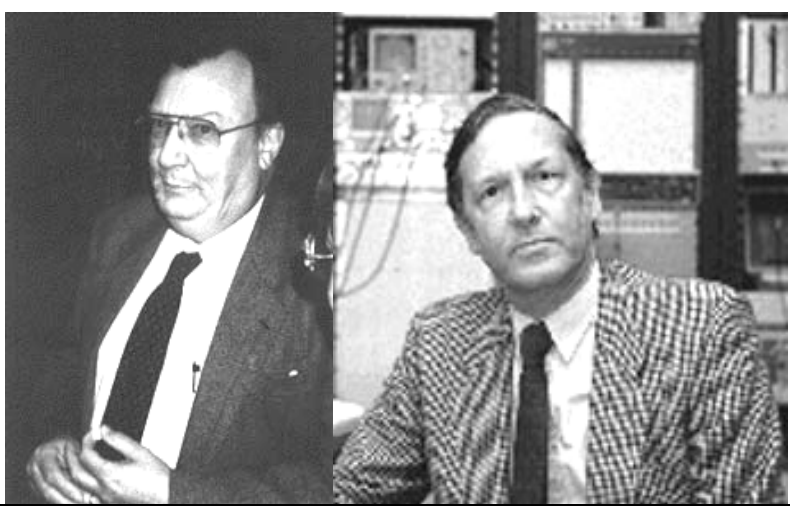

Figura 6. L'italià Carlo Rubbia (Esquerra) i I'holandès Simon van der Meer (dreta), guanyadors del premi Nobel de física del 1984. (Font: Fundació Nobel)

- 1989: Comença a funcionar el LEP, on s'acceleren i es fan col-lisionar frontalment electrons i positrons. Aviat els resultats confirmen que hi ha tres famílies de partícules, i només tres (fig. 7).

- 1990: Berners-Lee i Cailliau (fig. 8) creen la pàgina web amb la finalitat que els investigadors escampats pel món tinguessin accés fàcil i ràpid a les dades del CERN. 


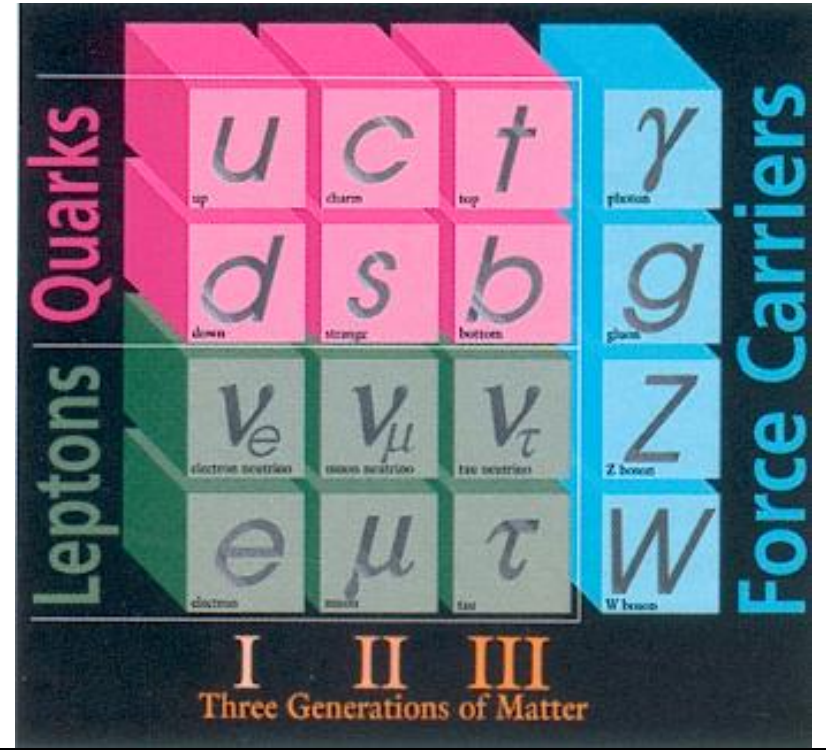

Figura 7. Les tres famílies de partícules: els quarks, els leptons i les partícules transmissores de forces. Al seu torn, les dues primeres d'aquestes famílies estan compostes per tres generacions: I, II i III.

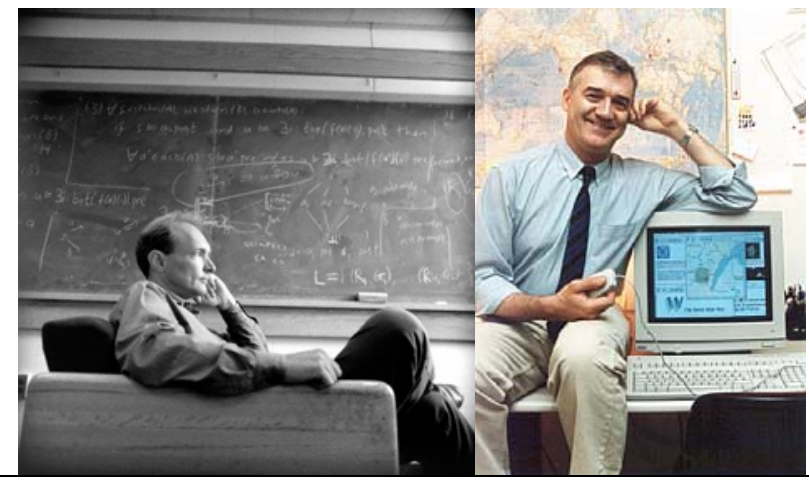

Figura 8. Tim Berners-Lee (esquerra) i Robert Cailliau (dreta).

- 1992: Charpak (fig. 9) rep el premi Nobel de física per la invenció i desenvolupament de detectors de partícules en el CERN. (De nacionalitat francesa, va néixer en una localitat polonesa que avui pertany a Ucraïna. Va lluitar a la resistència francesa i fou presoner al camp de concentració de Dachau).

- 1995: L'equip dirigit per Walter Oelert (fig. 10) sintetitza nou àtoms d'antihidrogen. L'antihidrogen té un antiprotó com a nucli i un positó constituint l'escorça. El 2002 ja es produeix antihidrogen en grans quantitats.

- 2000: Es troben evidències experimentals d'un nou estat de la matèria: el plasma de quarks i gluons. Una matèria 20 vegades més densa que la matèria nuclear. Es creu que va existir en els primers microsegons després del Big Bang, abans de formar-se les partícules de la matèria que coneixem actualment.

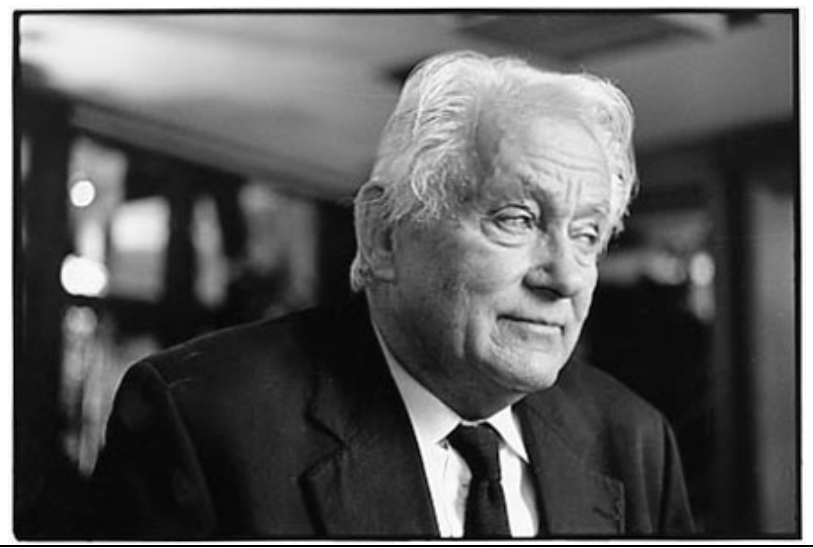

Figura 9. Georges Charpak, premi Nobel de física el 1992.

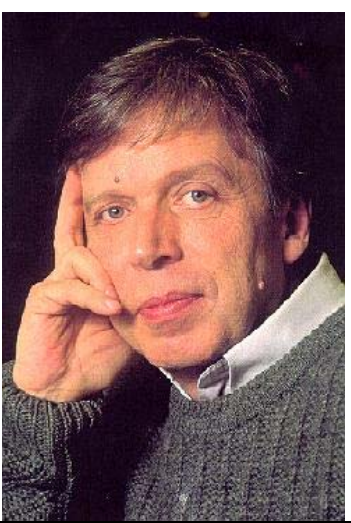

Figura 10. Walter Oelert.

- 2001: L'anàlisi de dades dóna suport a una teoria que explica que el nostre món sigui de matèria, tot i que la matèria i l'antimatèria apareguessin en quantitats idèntiques.

\section{El nou accelerador: I'LHC}

El novembre del 2000 es tanca el LEP per ser substituït per un altre accelerador, I'LHC (Large Hadron Collider, Gran Colisionador d'Hadrons).

Els hadrons són partícules sensibles a la força nuclear forta i estan formats per quarks (fig. 11). Poden ser de dues menes: els barions, formats per 3 quarks, i els mesons, formats per dos quarks (fig. 12). 


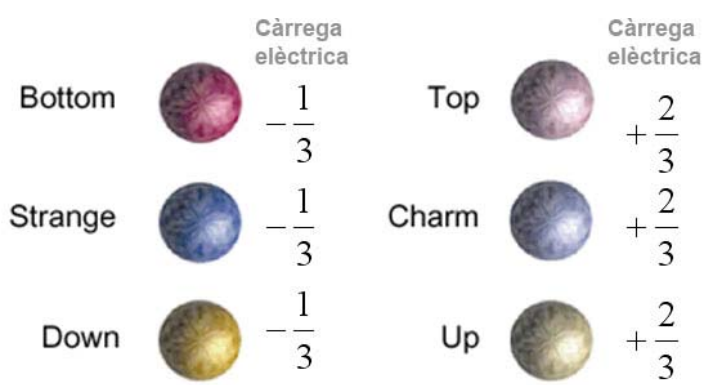

Figura 11. Els sis tipus de quarks que existeixen, amb la seva càrrega elèctrica. (Font: CERN)

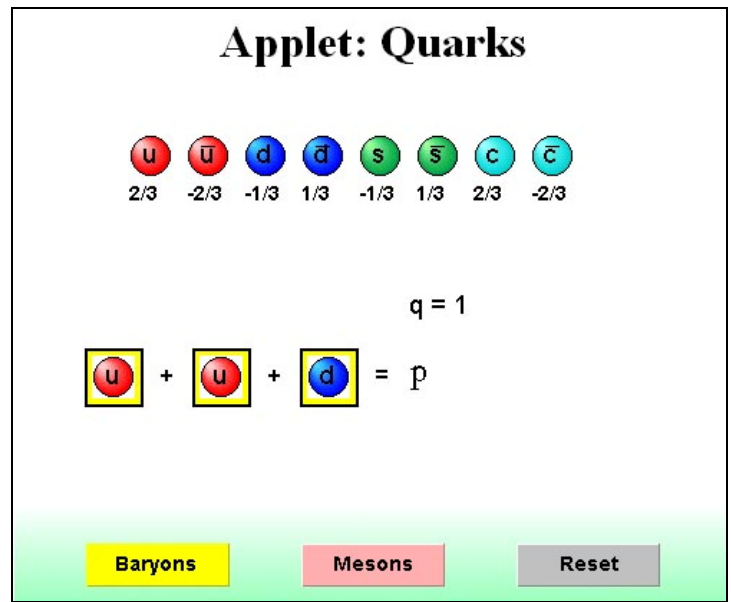

Figura 12. A la xarxa es poden trobar applets com aquest que simulen la combinació de quarks per obtenir partícules (barions i mesons) conegudes.

Per tant, aquesta vegada no es tracta d'accelerar electrons, sinó protons, que tenen una massa unes 1836 vegades més gran o, fins i tot, ions plom, molt més massius encara. Cada protó adquirirà una energia de $7 \mathrm{TeV}$, motiu pel qual en els xocs alliberaran $14 \mathrm{TeV}$. En canvi, quan es tracti d'ions plom, l'energia alliberada en la col-lisió serà de $1150 \mathrm{TeV}$.

Tant per accelerar-los com per desviar-los fa falta molta més força, força que hauran de fer uns camps magnètics molt més intensos que els del LEP i que només es poden crear amb superconductors. Es tracta de milers d'electroimants refrigerats amb heli líquid, a 1,9 K. Es pot dir que serà la màquina més freda de l'Univers.

\section{Què se n'espera,} de la nova màquina del CERN?

Bàsicament, contestar algunes de les grans preguntes de la física de partícules que queden sense resposta:

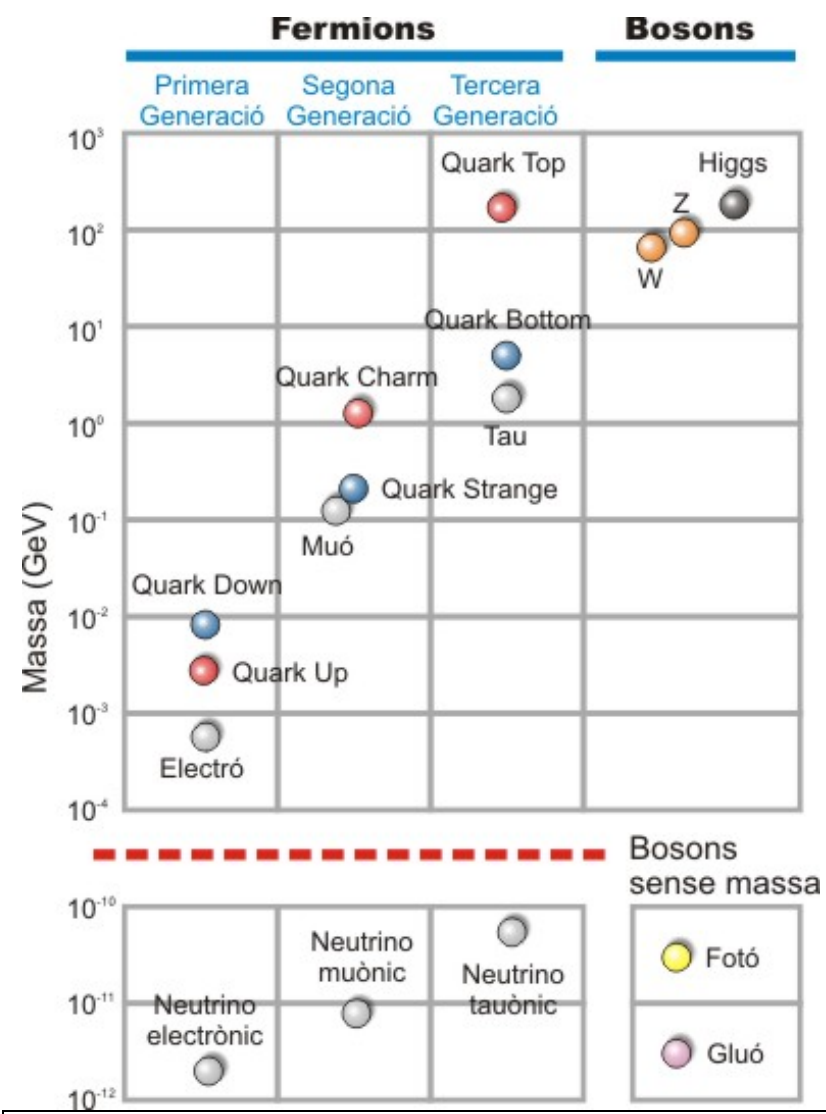

Figura 13. Massa de les diverses partícules elementals. El bosó de Higgs té una de les masses més elevades.

- Per què hi ha tres generacions de partícules elementals?

- Per quin motiu ha acabat predominant la matèria en el nostre univers enfront de l'antimatèria que s'hauria d'haver creat en la mateixa quantitat?

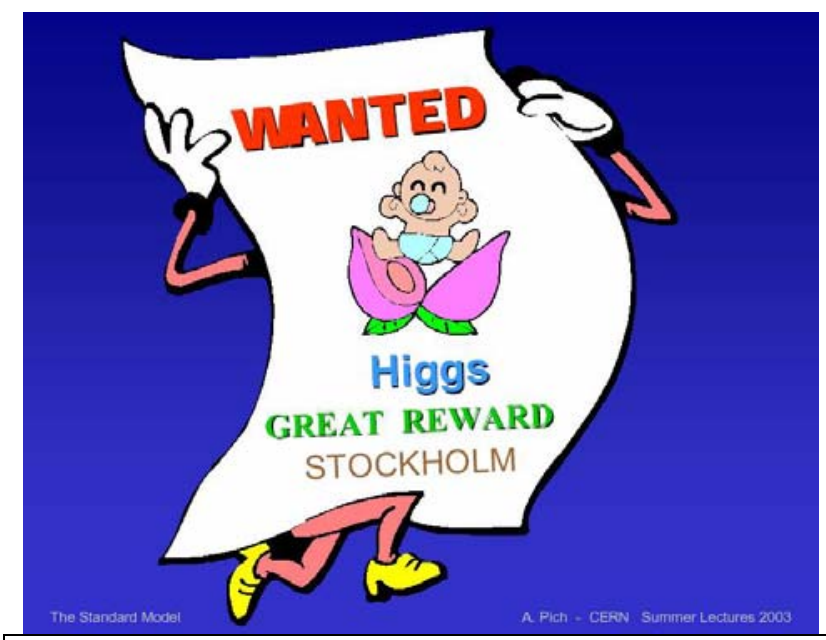

Figura 14. El descobriment de la partícula de Higgs pot significar una gran recompensa a Estocolm... 
- Per què existeix la massa de les partícules? En aquest sentit, s'espera poder detectar la partícula de Higgs (fig. 13), predita per la teoria. Això ajudaria a entendre l'origen de la massa i segurament suposaria un premi Nobel (fig. 14).

\section{I un nou recurs informàtic...}

La quantitat de dades que sortiran dels detectors del CERN serà tan enorme que superarà de molt la capacitat dels seus ordinadors. Per això, s'està creant una xarxa, mitjançant Internet, que distribueixi les tasques de càlcul i emmagatzematge de dades entre institucions de tot el món, fins i tot fent servir estàndards diferents: és l'anomenat projecte GRID (fig. 15), finançat per la Unió Europea que també s'utilitzarà en recerca biològica i en observació de la terra des de l'espai.

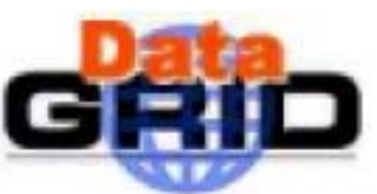

Figura 15. Logotip del projecte GRID. 